\title{
Prevalence and demographic characteristics of Hodgkin lymphoma in Colombia, according to Ministry of Health data
}

\author{
Mónica Arévalo-Zambrano ${ }^{1}$, Luisana Molina-Pimienta², Daniel G. Fernández-Ávila ${ }^{2,3}$ \\ ${ }^{1}$ Department of Internal Medicine, Hematology Unit, Hospital Universitario San Ignacio, Bogotá, Colombia \\ ${ }^{2}$ School of Medicine, Pontificia Universidad Javeriana, Bogotá, Colombia \\ ${ }^{3}$ Department of Internal Medicine, Rheumatology Unit, Hospital Universitario San Ignacio, Bogotá, Colombia
}

\begin{abstract}
Introduction: Hodgkin lymphoma accounts for approximately $10 \%$ of lymphoma cases. The epidemiology of Hodgkin lymphoma has always been a source of fascination to researchers due to its heterogeneous characteristics. Since 1993 in Colombia, the coverage of health services has been extended, and there is now an extensive registry of healthcare processes through the Social Protection Comprehensive Information System. The aim of our study was to calculate the prevalence, and describe the demographic characteristics, of Hodgkin lymphoma in Colombia.
\end{abstract}

Material and methods: This is a descriptive cross-sectional study with data from the Comprehensive Social Protection Information System of the Ministry of Health of Colombia between 2015 and 2019.

Results: 4,396 cases were identified, giving a prevalence of 8.9 per 100,000 inhabitants; of these, 55\% were men, with a male:female ratio of 1.2:1, with a higher prevalence in the 75-79 years age group. The departments with the highest prevalence were Risaralda (13.33), Bogotá D.C. (13.30), Boyacá (11.9), Quindío (11.49) and Santander (11.44).

Conclusions: Our prevalence is higher than that reported based on population-based cancer registries in Colombia 5.4 per 100,000 inhabitants between 2016 and 2020. We suggest that the differences found are due to the lack of population-based cancer registries in Colombian cities in which there is a higher prevalence of this entity and greater aging of the population.

Key words: Hodgkin lymphoma, epidemiology, Colombia, prevalence

Acta Haematologica Polonica 2021; 52, 6: 552-557

\section{Introduction}

Hodgkin lymphoma is a hematopoietic neoplasm characterized by the presence of Reed-Sternberg cells in an inflammatory infiltrate. Hodgkin lymphoma accounts for approximately $10 \%$ of lymphoma cases [1]. Its etiology is not clear, although it has been documented that immunosuppression and Epstein-Bárr virus (EBV) infection increase the risk of developing it [2-4].

This lymphoid malignancy involves peripheral lymph nodes and can also affect organs such as the liver, lung, and bone marrow [5]. It is subdivided according to its morphology and immunohistochemistry into classical (90\%) and nodular lymphocyte predominant (10\%) [6].

\footnotetext{
*Address for correspondence: Luisana Molina-Pimienta,

School of Medicine, Pontificia Universidad Javeriana, Carrera 7\#,

40-62 Bogota, 123456 Colombia,

e-mail: luisana.molina@javeriana.edu.co
}

Received: 28.12.2020

Accepted: 19.01.2021 
Epidemiological studies allow for estimation of the population affected by the disease and reflect the sociodemographic characteristics of those who suffer from it. Since Law 100 of 1993 was established in Colombia, the coverage of health services has been extended, and there is now an extensive registry of healthcare processes through the Social Protection Comprehensive Information System (known as SISPRO by its Spanish acronym) [6]. The purpose of this study was to establish the prevalence of Hodgkin lymphoma in Colombia and to describe the demographic characteristics of patients based on the official records of the Colombian Ministry of Health.

\section{Material and methods}

This was a descriptive cross-sectional study based on information from the Integrated Social Protection Information System (SISPRO) of the Colombian Ministry of Health. The Colombian healthcare system has one of the largest coverages in Latin America, reaching 95.97\% of the 49 million inhabitants, according to the most recent measurement made in May 2020 [7]. The Ministry of Health and Social Protection of Colombia has developed a tool for collecting and storing information, called SISPRO. This tool stores and processes the basic data that the General Social Security System in Health requires for management, regulation and control processes; the data is taken from the Individual Health Services Delivery Registry (known as RIPS by its Spanish acronym), which medical staff are obliged to fill out after each episode of outpatient or inpatient medical care. All healthcare providers (hospitals and health centers) are required by law to send such information to the SISPRO, using the corresponding International Classification of Diseases, $10^{\text {th }}$ revision (ICD-10) code for the primary diagnosis. Therefore, the said registry offers consolidated data of the entire population that demands services within the social security system in Colombia.

The SISPRO receives data from different sources, which are carefully checked by the Ministry of Health and Social Protection. The data sent is subject to continuous quality control tests. The data is checked against other sources of information (such as the population census, national health surveys, or other administrative records), before being entered into the SISPRO. If inconsistencies are detected, the data is sent back to the reporting institutions for review and correction, with the goal of improving the quality of data collected. The information contained in the SISPRO is accessible to the public via the online dynamic tables of the Ministry of Health of Colombia. For the present study, information was obtained from the care performed between 1 January, 2015 and 31 December, 2019, identifying the primary diagnosis for the care in accordance with the International Classification of Diseases, Tenth Revision (ICD-10) codes.

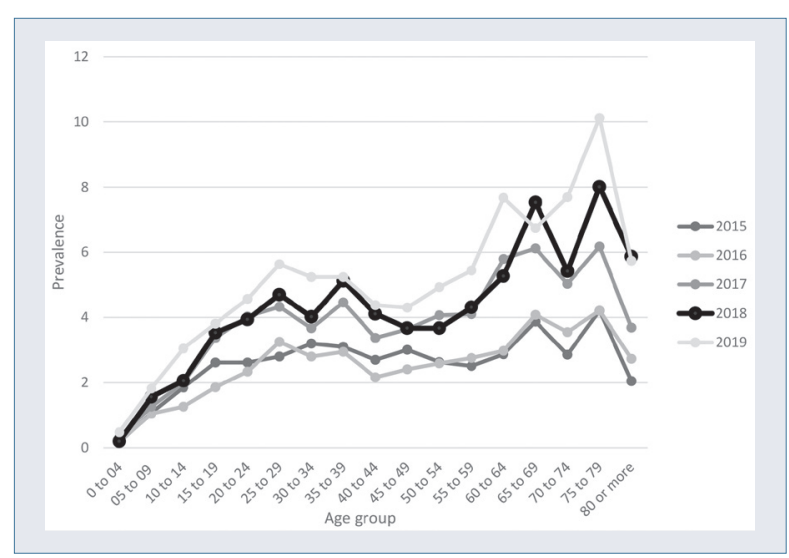

Figure 1. Age-specific unadjusted prevalence of patients with Hodgkin lymphoma 2015-2019. Prevalence is calculated per 100,000 inhabitants

The Individual Health Services Delivery Registry (RIPS) demographic information was obtained for patients diagnosed with Hodgkin lymphoma (ICD-10 codes: C81.0, C81.1, C81.2, C81.3, C81.4, C81.7, and C81.9).

Information regarding population size, geographic distribution by department, sex and age (classified by five-year groups), was obtained from the official projections of the National Administrative Department of Statistics (DANE), based on the projections of the 2005 national census [8]. DANE is the organization that processes official population statistics in Colombia. Hodgkin lymphoma prevalence rates standardized by age per 100,000 population were calculated from 2015 to 2019 (Figure 1). The numerator was the number of Hodgkin lymphoma cases in patients of any age (divided by five-year groups) which were reported to the SISPRO. The denominator was the number of inhabitants reported by DANE in the population projections for the entire country, and for each geographical area (Figure 2).

\section{Results}

Between 1 January, 2015 and 31 December, 2019, 4,396 cases of Hodgkin lymphoma were reported, giving a global prevalence of 8.9 per 100,000 inhabitants. Men accounted for $55 \%$ of cases, giving a male:female ratio of 1.2:1.

When analyzing the prevalence by five-year age groups, a gradual increase in people over 55 years of age was identified, with a higher prevalence in the $75-79$ years age group (22.2 per 100,000). Due to the characteristics of the registry, it was impossible to determine the incidence or the time of evolution of the disease.

The distribution of classical Hodgkin lymphoma by histopathological subtypes according to the ICD-10 code provided was nodular sclerosis $(67.7 \%)$, mixed cellularity (16.6\%), lymphocyte predominant (13.1\%), and lymphocyte depletion (2.6\%). 


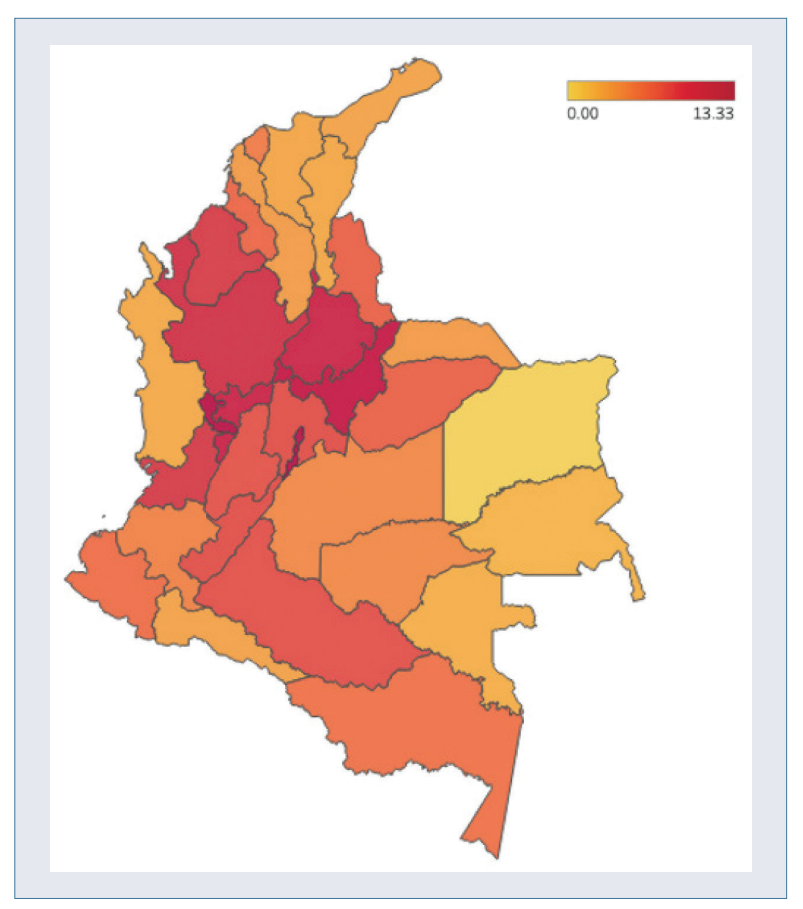

Figure 2. Geographical distribution of prevalence of Hodgkin lymphoma by department, adjusted to Colombian population. Prevalence is calculated per 100,000 inhabitants

An analysis of the distribution by department showed that the highest prevalences were registered in the most industrialized departments: Risaralda (13.33), Bogotá D.C. (13.30), Boyacá (11.9), Quindío (11.49) and Santander (11.44). Departments such as Archipelago of San Andrés, Providencia and Santa Catalina, Guainía, Vaupés, Cesar and Magdalena had the lowest prevalence.

\section{Discussion}

Hodgkin lymphoma accounts for $10 \%$ of lymphomas and $0.6 \%$ of cancers diagnosed each year worldwide [9]. Its prevalence has been described in various parts of the world through population-based cancer registries, but there have been few studies on its prevalence in each of the different countries. Latin America is undergoing an accelerated process of demographic transition, with greater aging of the population, which leads to an increase in the prevalence of low mortality entities such as Hodgkin lymphoma [10].

A study conducted in the United States based on health services information systems (Medicare databases), reported a prevalence of 46.9 cases per 100,000 inhabitants between 2013 and 2014 [11]. The United Kingdom's population-based Hematological Malignancy Research Network found a 5-year prevalence of 12.9 cases per 100,000 inhabitants [12]. Our study based on SISPRO data reports a prevalence of 8.9 cases per 100,000.
Hodgkin lymphoma is classified as either classical or nodular lymphocyte predominant. The four subtypes of classical Hodgkin lymphoma differ in their presentation, epidemiology and association with the EBV [13]. In general, patients with lymphocyte depletion and mixed cellularity subtype have a worse prognosis [14]. In a study of 454 patients in Turkey, the following description of subtypes was made: nodular sclerosis (52.7\%), mixed cellularity (32.5\%), lymphocyte-rich (8.5\%), and lymphocyte depletion (4.2\%) [15]. In our study, the most frequent subtype was nodular sclerosis $(67.7 \%)$, followed by mixed cellularity (16.6\%), lymphocyte-rich (13.1\%) and lymphocyte depletion (2.6\%); the frequency of presentation of the subtypes varies from that of the published studies because the assignment of the subtype depends upon the attending physician during the consultation.

Hodgkin lymphoma occurs more often in men, with the exception of the nodular sclerosis subtype, which mostly affects young women, and its presentation by age in industrialized countries shows a bimodal curve, with the most significant peak in young adults ( 15 to 34 years) and the second most significant in those over 50 [16]. Our study showed that the greatest number of cases occurred in adults older than 75 years, which is probably related to the aging of our country's population, and to the fact that the population includes surviving patients, because it was impossible to determine whether it was a new case or a previously treated patient.

The study by Glaser et al. [17] reported how the place of birth influences the incidence of Hodgkin lymphoma, and found a higher incidence in Hispanics and children of Hispanics in the second bimodal peak. Previous studies have shown that the incidence rate is higher than the mortality rate, considering that a high percentage of Hodgkin lymphoma patients live long enough to die from other causes, such as in the series of the Memorial Sloan Kettering Cancer Center, in which a 22-year follow-up found a 30\% mortality, $47 \%$ of which was attributable to other causes [18].

It has been reported that 1,700 cases occur every year in the United Kingdom, with a slight predominance in men (1.2:1), and a greater number of cases during the fourth and fifth decades of life [19]. It was estimated that in 2017, 8,260 new cases of Hodgkin lymphoma were diagnosed in the United States [20].

The prevalence for the population reported in the Global Cancer Observatory GLOBOCAN between 2016 and 2020, by the International Agency for Research on Cancer (IARC) in Colombia, is 5.4 per 100,000 inhabitants. The following is the prevalence per 100,000 inhabitants found in other countries: Brazil (5.2), Argentina (8.4), Portugal (8.4) Spain (11.1), France (12.4), United Kingdom (13.9), and Italy (13.9) [21].

The United States National Cancer Institute ( $\mathrm{NCl}$ ), through the Surveillance, Epidemiology, and End Results 


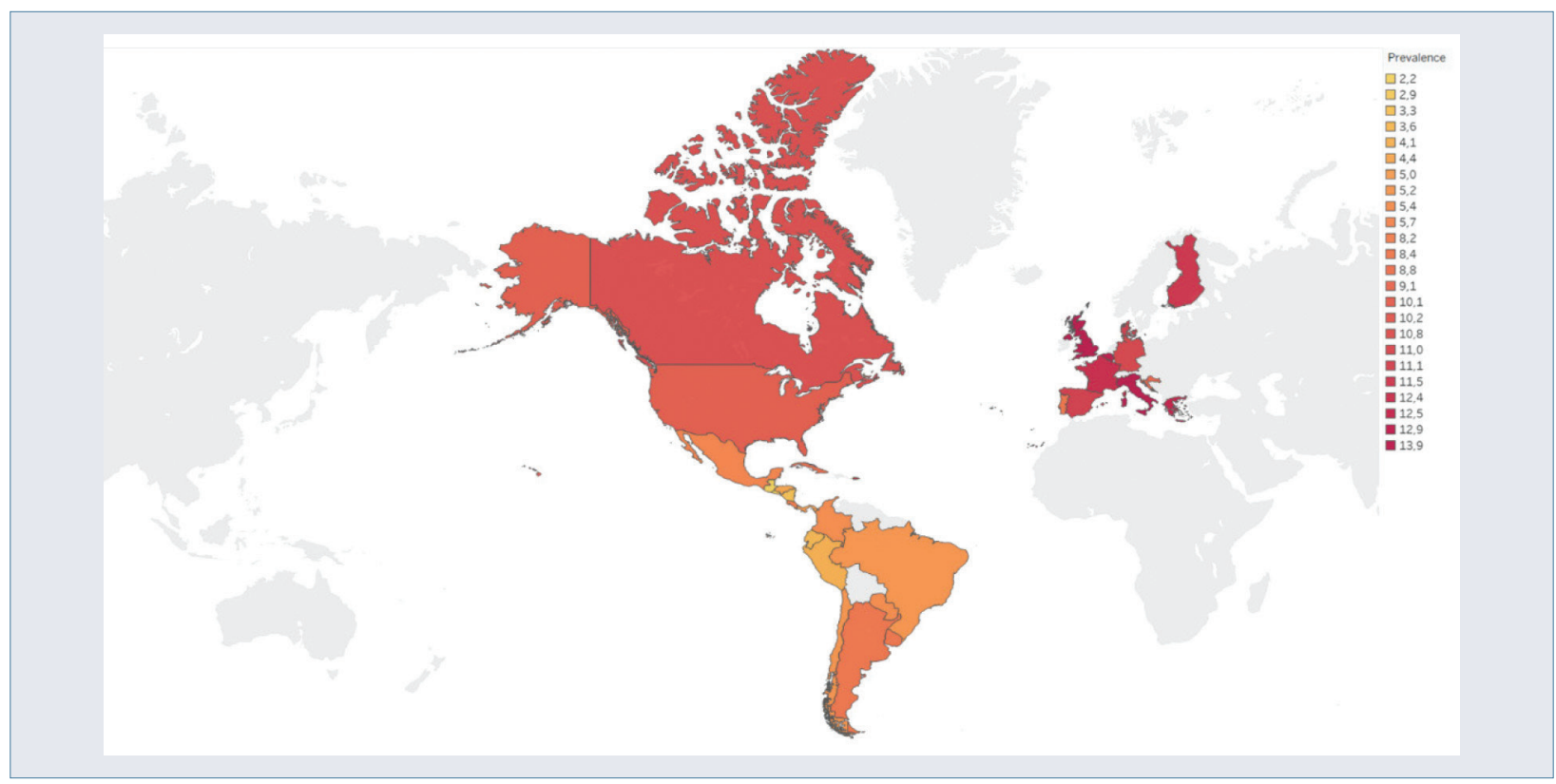

Figure 3. Prevalence of Hodgkin lymphoma in several countries. Prevalence is calculated per 100,000 inhabitants (source: the Global Cancer Observatory)

(SEER) Program, reported that by 2017 there were 215,531 people living in this country with Hodgkin lymphoma [22].

Population-based cancer registries from the cities of Cali, Pasto, Manizales and Bucaramanga have been the only sources of information on cancer in Colombia in recent years [23]. However, there is no detailed information on Hodgkin lymphoma from other major cities with particular sociodemographic characteristics, including Bogotá and Medellín, the two largest cities in Colombia. The inclusion of these two cities, and other cities in general, could explain the higher rate of Hodgkin lymphoma found in our study compared to the results previously presented by the IARC in Colombia through the Global Cancer Observatory (GLOBOCAN). This study carried out in Colombia allows us to determine the prevalence in all departments of the country, to describe the demographic characteristics of the patients, and to compare them to the statistics of population-based cancer registries.

The last report of the National Cancer Institute of Colombia, for the 2007-2011 five-year period, was carried out using the IARC methods to estimate survival in countries with a high human development index. These methods assume that cancer survival for Colombia by location is the same as that obtained from the weighted average of the absolute survival for each location recorded in the cities of Hong Kong, Qidong, Shanghai and Tianjin, in China; Barshi, Bhopal, Chennai, Karunagappally and Mumbai, in India; Chiang Mai, Khon Kaen, Lampang and Songkhla, in Thailand, and the city of Kampala, in Uganda. For the estimation of prevalence, it is assumed that the annual incidence is constant during the period. During this five-year period, a total of 1,086 cases were reported, $66 \%$ of which were in men; the departments with the highest number of cases were Risaralda, Bogotá D.C., Boyacá, Quindío and Santander; the lowest number of cases was registered in the Archipelago of San Andrés, Providencia and Santa Catalina, Guainía, Vaupés, Cesar and Magdalena [24].

Unlike other studies carried out, our study evaluated all medical care performed in the country in which Hodgkin lymphoma has been considered as the main diagnosis. Taking into account the high coverage of the healthcare system, in order to calculate the prevalence it is not necessary to make estimates through population registries. The difference in prevalence in our study may be related to the greater availability of data from cities with a greater number of cases. However, a limitation of our study is the possible incorrect reporting by doctors at the time of entering the ICD-10 code in the medical records, as well as the fact that they do not specify how the diagnosis was performed. The nature of the available information does not allow us to calculate the time of evolution of the disease or to estimate its incidence and severity.

The present study shows the prevalence of Hodgkin lymphoma through the report and registry available in the SISPRO of the Ministry of Health of Colombia, and constitutes one of the different ways of calculating the prevalence and epidemiologically assessing this disease; in addition, it provides complementary information to other methodological approaches, to establish the frequency of this disease in our population. 
Colombia is a middle-income country with limited resources affecting research. The starting point of this work was to make a register with more reliable data about the cancer situation nationwide, with a specific interest in lymphoma. It is extremely important to perform a population analysis in middle-income countries such as this report, since we have too little information to allow analysis of the disease impact and any possible actions in terms of public health geared towards improving treatment for hematological neoplasm patients. Colombia also requires more robust cancer registries to provide more reliable information about what is happening in the country. As we have a registry seeded by all the health professionals around the country, we invite other colleagues to perform a more precise registration to improve and take advantage of the information provided.

\section{Conclusions}

The present study provides demographic and epidemiological information regarding Hodgkin lymphoma in Colombia. The figures are higher than those reported in the literature. Our study shows information taken from the database of the Ministry of Health of Colombia, with which demographic and epidemiological analyses of the population, and projections for the care of patients in our country, are made.

\section{Authors' contributions}

DF - study design and administrative support; MA - important clinical data; LM - developed first draft of manuscript; DF and MA - assisted in writing and editing of manuscript. All authors - data analysis and interpretation, data checkup, critical revision and final approval.

\section{Conflict of interest \\ None.}

\section{Financial support}

None.

\section{Ethics}

The work described in this article has been carried out in accordance with The Code of Ethics of the World Medical Association (Declaration of Helsinki) for experiments involving humans; EU Directive 2010/63/EU for animal experiments; Uniform Requirements for manuscripts submitted to Biomedical journals.

\section{References}

1. Shanbhag S, Ambinder RF. Hodgkin lymphoma: a review and update on recent progress. CA Cancer J Clin. 2018; 68(2): 116-132, doi: 10.3322/caac.21438, indexed in Pubmed: 29194581.

2. Gérard L, Galicier L, Boulanger E, et al. Improved survival in HIV-related Hodgkin's lymphoma since the introduction of highly active antiret- roviral therapy. AIDS. 2003; 17(1): 81-87, doi: 10.1097/00002030200301030-00011, indexed in Pubmed: 12478072.

3. Landgren 0 , Engels EA, Pfeiffer RM, et al. Autoimmunity and susceptibility to Hodgkin lymphoma: a population-based case-control study in Scandinavia. J Natl Cancer Inst. 2006; 98(18): 1321-1330, doi: 10.1093/jnci/djj361, indexed in Pubmed: 16985251.

4. Chang KL, Albujar PF, Chen YY, et al. High prevalence of Epstein-Barr virus in the Reed-Sternberg cells of Hodgkin's disease occurring in Peru. Blood. 1993; 81(2): 496-501, doi: 10.1182/blood. v81.2.496.496.

5. Küppers R, Engert A, Hansmann ML. Hodgkin lymphoma. J Clin Invest. 2012; 122(10): 3439-3447, doi: 10.1172/JCI61245, indexed in Pubmed: 23023715.

6. Wang HW, Balakrishna JP, Pittaluga S, et al. Diagnosis of Hodgkin lymphoma in the modern era. Br J Haematol. 2019; 184(1): 45-59, doi: 10.1111/bjh.15614, indexed in Pubmed: 30407610.

7. Ministerio de salud C. Cifras de aseguramiento en salud 2020. https://www.minsalud.gov.co/proteccionsocial/Paginas/cifras-aseguramiento-salud.aspx (December 28, 2020).

8. Departamento Nacional de Estadítica. Archivo de estimación y proyección de la población nacional, departamental y municipal total por área 1985-2020. Investig Proyecciones Población En Colomb 2019. https://www.dane.gov.co/index.php/estadisticas-por-tema/ demografia-y-poblacion/proyecciones-de-poblacion (December 28, 2020).

9. Matsuki E, Younes A. Lymphomagenesis in Hodgkin lymphoma. Semin Cancer Biol. 2015; 34: 14-21, doi: 10.1016/j.semcancer. 2015.02.002, indexed in Pubmed: 25725205.

10. Albala C, Vio F, Yáñez M. [Epidemiological transition in Latin America: a comparison of four countries] [Article in Spanish]. Rev Med Chil. 1997; 125(6): 719-727, indexed in Pubmed: 9580335.

11. Lin J, Siegartel LR, Lingohr-Smith M, et al. Using health care claims data to assess the prevalence of Hodgkin lymphoma and relapsed or refractory Hodgkin lymphoma in the United States. Clin Ther. 2017; 39(2): 303-310, doi: 10.1016/j.clinthera.2016.12.010, indexed in Pubmed: 28065438.

12. Smith $A$, Crouch $S$, Lax $S$, et al. Lymphoma incidence, survival and prevalence 2004-2014: sub-type analyses from the UK's Haematological Malignancy Research Network. Br J Cancer. 2015; 112(9): 1575 -1584, doi: 10.1038/bjc.2015.94, indexed in Pubmed: 25867256.

13. Townsend W, Linch D. Hodgkin's lymphoma in adults. Lancet. 2012; 380(9844): 836-847, doi: 10.1016/S0140-6736(12)60035-X, indexed in Pubmed: 22835602.

14. Küppers R. The biology of Hodgkin's lymphoma. Nat Rev Cancer. 2009; 9(1): 15-27, doi: 10.1038/nrc2542, indexed in Pubmed: 19078975.

15. Yildirim M, Yildiz M, Kurtoglu E, et al. Epidemiology and histological subtypes of Hodgkin lymphoma in the south-west of Turkey. Gulhane Med J. 2012; 54(3): 216, doi: 10.5455/gulhane.25722.

16. Salati M, Cesaretti M, Macchia M, et al. Epidemiological overview of Hodgkin lymphoma across the Mediterranean Basin. Mediterr J Hematol Infect Dis. 2014; 6(1): e2014048, doi: 10.4084/MJHID.2014.048, indexed in Pubmed: 25045456.

17. Glaser SL, Clarke CA, Chang ET, et al. Hodgkin lymphoma incidence in California Hispanics: influence of nativity and tumor Epstein-Barr virus. Cancer Causes Control. 2014; 25(6): 709-725, doi: 10.1007/ s10552-014-0374-6, indexed in Pubmed: 24722952.

18. MacMahon B. Epidemiology of Hodgkin's disease. Cancer Res. 1966; 26(6): 1189-1201, indexed in Pubmed: 5329907. 
19. Bartlett NL, Foyi KV. 105.Hodgkin lymphoma. https://www.sciencedirect.com/sdfe/pdf/download/eid/3-s2.0-B9781455728657001053/ first-page-pdf (December 28, 2020).

20. Fields P, Wrench D. Hodgkin lymphoma. Medicine. 2017; 45(5): 305-310, doi: 10.1016/j.mpmed.2017.02.003.

21. IARC. Estimated number of prevalent cases (5-year) as a proportion in 2020, Hodgkin lymphoma, both sexes, all ages n.d. https://gco.iarc.fr (January 4, 2020).
22. National Cancer Institute. SEER Cancer Stat Facts: vulvar cancer. Surveillance, Epidemiol End Results Progr 2020. https://seer.cancer. gov (November 20, 2019).

23. Bravo LE, Muñoz N, Sanchez Gl, et al. Epidemiology of cervical cancer in Colombia. Colomb Med (Cali). 2012; 43(4): 298-304, indexed in Pubmed: 24893303.

24. Pardo C, Cendales R. Incidencia, mortalidad y prevalencia de cáncer en Colombia, 2007-2011. Colomb Med (Cali). 2018; 49(1): 16-22, doi: 10.25100/cm.v49i1.3596, indexed in Pubmed: 29983460. 